\title{
Melt and One-Pot Solution Synthesis of Thermally Stable, Organosoluble and Photocurable Acidic Polyimides
}

\author{
Genggongwo Shi'1,2, Jeseob Kim², Kyeongha Baek ${ }^{1}$, Jun Bae ${ }^{3}$, Lee Soon Park ${ }^{*}$ \\ ${ }^{1}$ School of Material Science and Engineering, Ulsan National Institute of Science and Technology (UNIST), Ulsan, Korea \\ ${ }^{2}$ CCTech. Co. Ltd, Hwaseong, Korea \\ ${ }^{3}$ DuksanNeolux Co., Ltd., Cheonan, Korea \\ Email: *parkls@un ist.ac.kr
}

How to cite this paper: Shi, G., Kim, J. Baek, K., Bae, J. and Park, L.S. (2019) Melt and One-Pot Solution Synthesis of Thermally Stable, Organosoluble and Photocurable Acidic Polyimides. Materials Sciences and Applications, 10, 709-720.

https://doi.org/10.4236/msa.2019.1011051

Received: October 17, 2019

Accepted: November 15, 2019

Published: November 18, 2019

Copyright (c) 2019 by author(s) and Scientific Research Publishing Inc. This work is licensed under the Creative Commons Attribution International License (CC BY 4.0).

http://creativecommons.org/licenses/by/4.0/

\begin{abstract}
Polyimides are well known for their high chemical and thermal stability. However, a few polyimide samples have been reported which are completely soluble in such environmentally friendly and common organic solvent as propyleneglycol monomethyl ether acetate (PGMEA). In this work thermally stable, organosoluble and photocurable acidic polyimides were synthesized by simple and cost effective one-pot solution method. They polyimides obtained by this method showed much higher thermal stability ( $1 \mathrm{wt} \%$ loss temperature $345^{\circ} \mathrm{C}$ ) than melt polymerized polyimides owing to the photocrosslinking reactions by the terminal double bonds.
\end{abstract}

\section{Keywords}

Polyimide, Melt Polymerization, One-Pot Solution Polymerization, Thermal Stability, Organosoluble Polyimide, Photocurable Polyimide

\section{Introduction}

Polyimides are widely used in electronic devices [1], battery separators [2] and gas adsorption [3] due to the chemical inertness and superior thermal stability [4]. Besides these applications, polyimides of relatively lower molecular weight can be served as thermal stabilizers or binder polymers in photoresists to be developed by basic aqueous solutions. Therefore, the organosolubility and acidity (usually represented by phenolic - $\mathrm{OH}$ and/orcarboxyl groups) of polyimides are becoming important. Most thermally stable polyimides are made from aromatic diamines and dianhydrides which hinder their solubility in a common organic 
solvent, among which only small parts of them are soluble in polar solvents such as NMP, DMAc and THF [5]. Photocuring not only gives a way for the polyimide to serve as a binder polymer in typical photoresists, but also reinforces the overall thermal stability to a great extent. Polyimides which have substituents like acrylate or methacrylate, i.e., photocurable polyimides have been utilized in gate insulators for thin-film transistors [6] and 3D printing process [7] [8].

In this work, we report the melt and one-pot solution syntheses of acidic organosoluble and photocurable new polyimides and analyzed their thermal stability before and after UV curing for potential application in areas such as photoresist binder polymer or thermal stabilizer developable with aqueous base.

\section{Experimental}

\subsection{Materials}

All the reagents and solvents were purchased from commercial sources and used directly in the experiments without further purification. Abbreviations of the compounds are as following: 4,4'-(Hexafluoroisopropylidene)diphthalic Anhydride (6FDA); 5-(2,5-dioxotetrahydrofuryl)-3-methyl-3-cyclohexene-1,2-dicarboxylicanhydride (MCDA); 2,2-Bis[4-(4-aminophenoxy)phenyl]hexafluoropropane (BF6); 2,2'-bis(3-amino-4-hydroxy-phenyl)-hexafluoropropane (AH6); 3,5-diaminobenzoic acid (DAB); 5-aminoisophthalic acid (AIPA); 4-amino benzoic acid (4-AB); 3-amino benzoic acid (3-AB); glycidyl methacrylate (GMA); Pentaerythritoltriacrylate (PETA); 3,5-Di-tert-4-butylhydroxytoluene (BHT); tetrabutylphosphonium bromide (TBPB); dimethyl acetamide (DMAc); propyleneglycolmonomethylether acetate (PGMEA).

\subsection{Syntheses of Polyimides}

\subsubsection{Melt Polymerization}

Typical reaction scheme: Certain molar ratio of dianhydrides, diamines and monoamine powders were well mixed by a mortarin a metal cup and then the metal cup was placed into $240^{\circ} \mathrm{C}$ electric oven with $\mathrm{N}_{2}$ gas flowing for certain reaction time. Afterwards, the metal cup was taken out of the oven, cooled down in $\mathrm{N}_{2}$ atmosphere to room temperature and the resulting polyimides were recovered and pulverized to fine particles (Figure 1 and Figure 2).

\subsubsection{Solution Polymerization}

One-pot solution polymerization of SAM intermediate and SAMG polyimide.

MCDA $30 \mathrm{wt} \%$ solution $(10 \mathrm{mmol})$ in DMAc was added into $30 \mathrm{wt} \%$ AH6 (9 $\mathrm{mmol}$ ) and AIPA ( $2 \mathrm{mmol}$ ) solution of DMAc under ice bath and stirred for $1 \mathrm{~h}$. Then the temperature was raised up to $45^{\circ} \mathrm{C}$ and stirred for $23 \mathrm{~h}$, followed by stirring at $130^{\circ} \mathrm{C}$ for $24 \mathrm{~h}$ to afford SAM which was used directly in the next step without further purification. To the DMAc solution of SAM was added $30 \mathrm{wt} \%$ GMA (4 mmol), BHT (0.02 mmol) and TBPB (0.04 mmol) in DMAc solutions. 

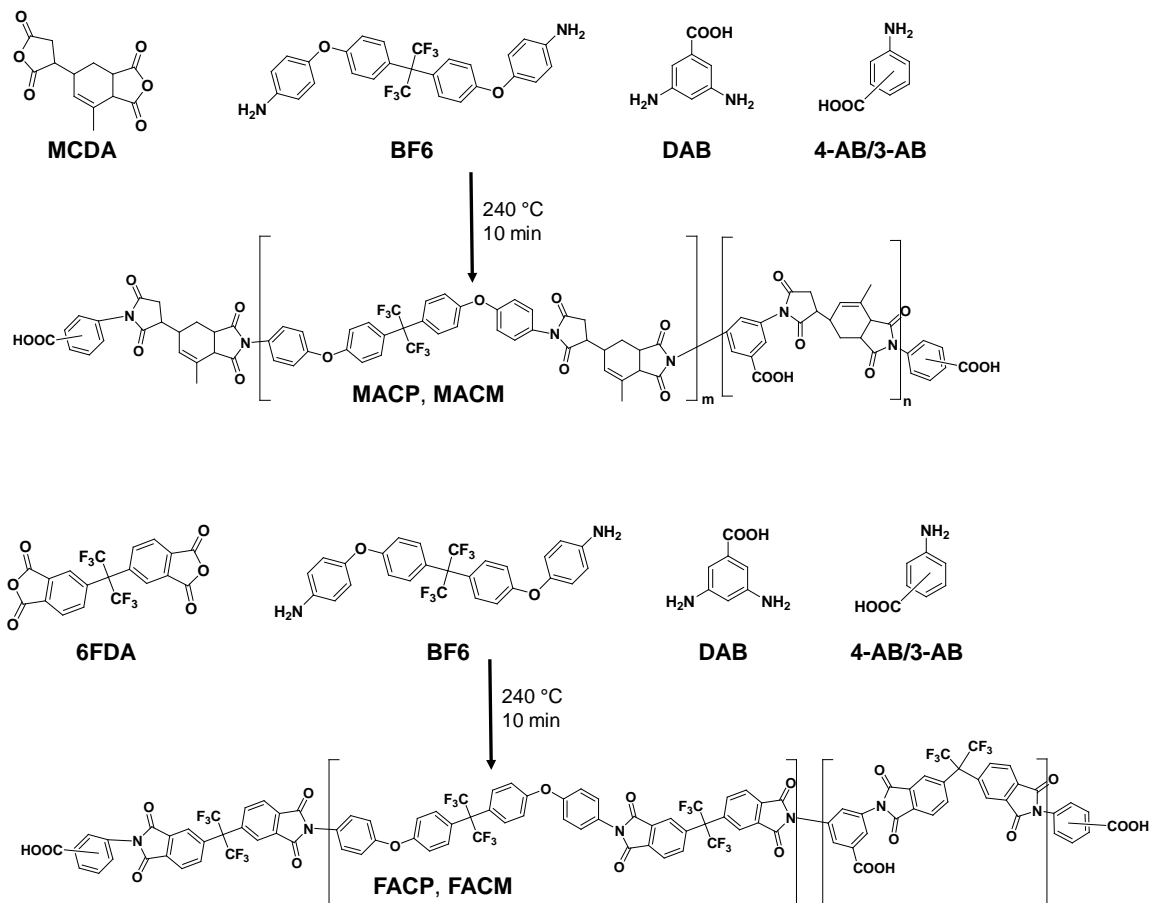

Figure 1. Synthesis of MACP (M) and FACP(M) series polyimides by melt polymerization.

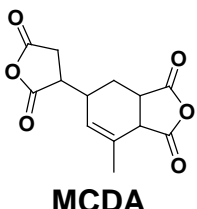<smiles>CC(c1ccc(Oc2ccc(N)cc2)cc1)(c1ccc(Oc2ccc(N)cc2Br)cc1)C(F)(F)F</smiles>
MCDA $240^{\circ} \mathrm{C}$ $10 \sim 60 \mathrm{~min}$

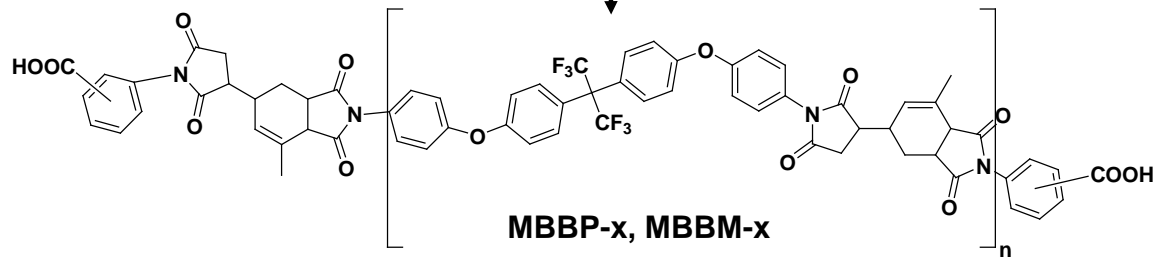

Figure 2. Synthetic scheme of MBBP and MBBM series polyimides by melt polymerization.

The mixture solution was stirred at $90^{\circ} \mathrm{C}$ for $3 \mathrm{~h}$ to afford SAMG which was used in the test without further purification (Figure 3).

One-pot solution polymerization of PAMG and MAMG series polyimides.

MCDA powder ( $5 \mathrm{mmol}$ ) was added into PGMEA solution of AH6 (4 mmol) and $4-\mathrm{AB}(2 \mathrm{mmol})$ with an overall concentration of $25 \mathrm{wt} \%$. The mixture was stirred at RT for $1 \mathrm{~h}$, at $45^{\circ} \mathrm{C}$ for $23 \mathrm{~h}$ followed by $130^{\circ} \mathrm{C}$ for $24 \mathrm{~h}$. After cooling, to the mixture was added $25 \mathrm{wt} \%$ of GMA $(2 \mathrm{mmol})$ in PGMEA, BHT $(0.01$ $\mathrm{mmol})$ and ТВPB $(0.02 \mathrm{mmol})$. The solution was stirred at $90^{\circ} \mathrm{C}$ for $3 \mathrm{~h}$ to afford 

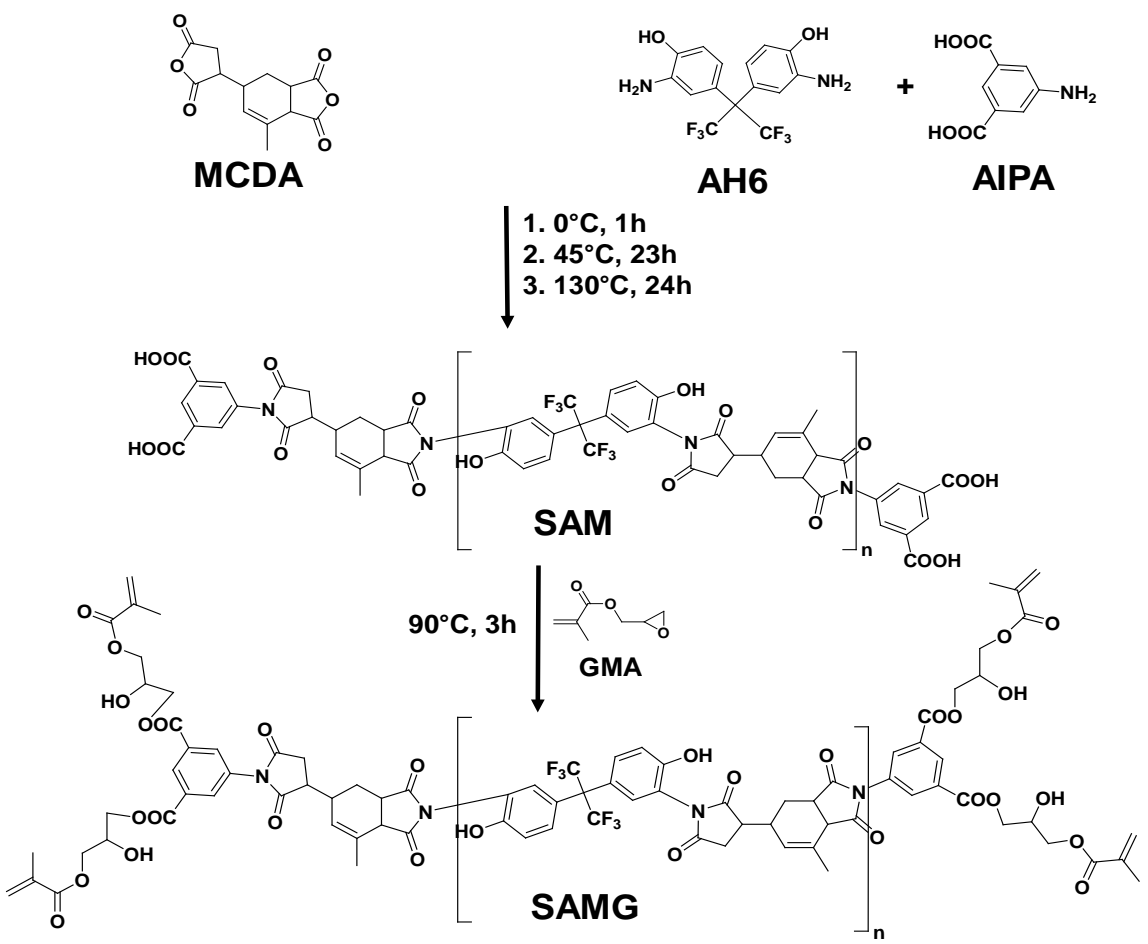

Figure 3. Synthetic scheme of SAMG polyimide.

PAMG which was used without further purification. MAMG was synthesized using $3-\mathrm{AB}$ instead of $4-\mathrm{AB}$ with the same scheme (Figure 4).

\subsection{Evaluation of Thermal Stability with Thermogravimetric Analysis (TGA)}

For a TGA test of solution polyimide sample (without UV curing), the solution was spin-coated on glass substrates, pre-baked $\left(110^{\circ} \mathrm{C}, 100 \mathrm{~s}\right)$ and subjected to post-cure $\left(250^{\circ} \mathrm{C}, 30 \mathrm{~min}\right)$. After cooling, the film on glass substrates was scratched off as powder for TGA test.

For the TGA test of UV-cured polyimide samples, photoinitiator (SPI-03, 3 wt\%) was added in the polyimide solution; and the solution was spin-coated on glass substrates, pre-baked $\left(110^{\circ} \mathrm{C}, 100 \mathrm{~s}\right)$, UV exposed $(80 \mathrm{~mJ})$ and subjected to post-cure $\left(250^{\circ} \mathrm{C}, 30 \mathrm{~min}\right)$. After cooling, the film on glass substrates was scratched off as powder for TGA test.

\section{Results and Discussions}

\subsection{Melt Polymerization of Polyimides}

In our previous work we used various combinations of dianhydrides, diamines and monoanhydrides to synthesize polyimides soluble in common organic solvents (PGMEA) by melt polymerization [9]. It was found that the polyimide (FTAP-1) obtained by the combination of dianhydride with $-\mathrm{CF}_{3}$ groups (6FDA), diamine with $-\mathrm{CF}_{3}$ groups (AH6) and monoanhydride (PEPA) monomers as shown in Figure 5 exhibited good solubility in PGMEA solvent. 


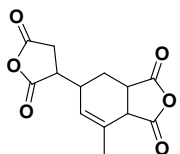

MCDA

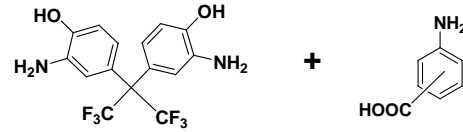

AH6

\section{$4-A B / 3-A B$}

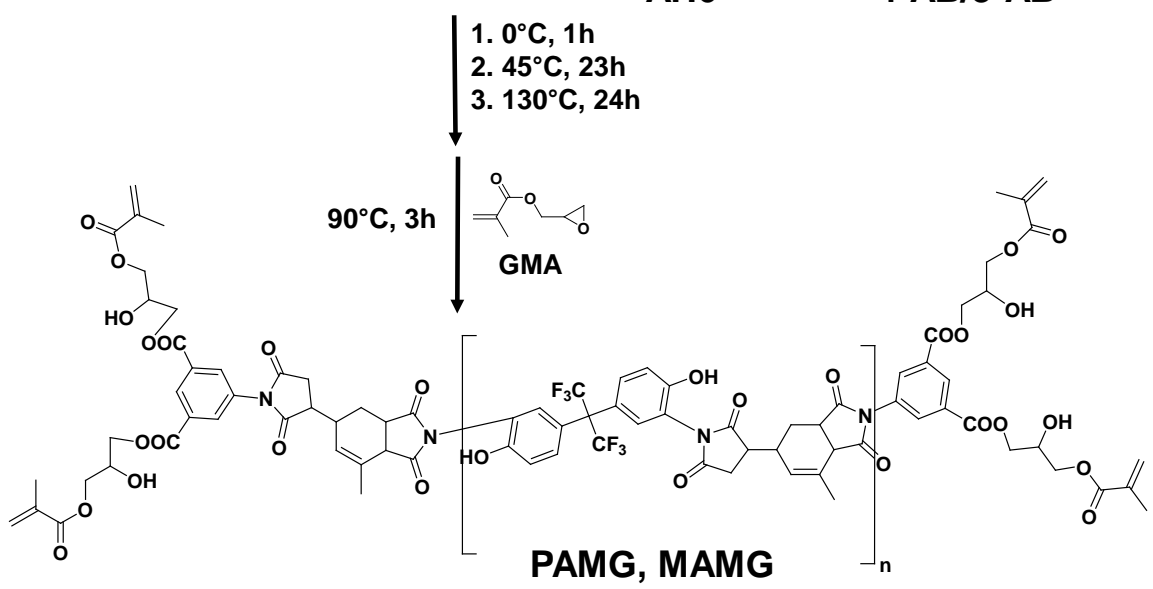

Figure 4. Synthetic scheme of PAMG and MAMG series polyimides.

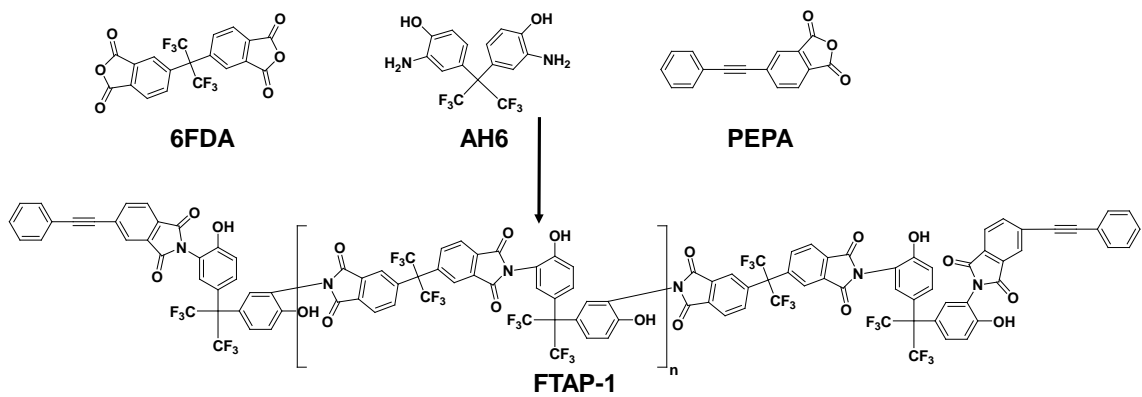

Figure 5. The structures of polyimide (FTAP-1) obtained from 6FDA, AH6 and PEPA monomers.

The PGMEA soluble polyimide (FTAP-1), however, could be obtained only at the melt polymerization condition at $240^{\circ} \mathrm{C}$ for a short reaction time of $10 \mathrm{~min}$, thus resulting in low molecular weight polyimides. When the melt polymerization temperature was above $240^{\circ} \mathrm{C}$ or the time was over $10 \mathrm{~min}$, the polyimides obtained showed insolubility in PGMEA. This result could be attributed to the cross-linking reaction between the synthesized FTAP-1 polyimides through the dehydration of phenolic -OH groups in the AH6 units.

One plausible synthesis of polyimide by melt polymerization to avoid the problem of FTAP-1 is shown in Figure 1 with the reaction condition given in Table 1. In this case we used MCDA and 6FDA as dianhydride monomers, BF6 and $\mathrm{DAB}$ (diaminobenzoic acid) as diamine comonomers and 4- $\mathrm{AB}$ (4-aminobenzoic acid) or 3-AB (3-aminobenzoic acid) as monoamines to control the molecular weight of the resulting polyimides as well as maintain certain acidity by $-\mathrm{COOH}$ groups. In these melt polymerizations, in contrast to the previous polyimides, the monoamines (4- $\mathrm{AB}$ or $3-\mathrm{AB}$ ) were used to give polyimides with carboxyl terminal groups. The carboxyl groups will also be present in the main chain of 
Table 1. The synthetic conditions of polyimides and their solubility in organic solvents.

\begin{tabular}{|c|c|c|c|c|c|c|}
\hline Sample & $\begin{array}{c}\text { Dianhydride } \\
(\mathrm{mmol})\end{array}$ & $\begin{array}{c}\text { Diamines } \\
(\mathrm{mmol})\end{array}$ & $\begin{array}{l}\text { Monoamine } \\
(\mathrm{mmol})\end{array}$ & Condition & $\begin{array}{c}30 \% \\
\text { PGMEA }\end{array}$ & $\begin{array}{c}30 \% \\
\text { DMAc }\end{array}$ \\
\hline MACP & \multirow{2}{*}{ MCDA (5) } & & $4-\mathrm{AB}(2)$ & \multirow{4}{*}{$\begin{array}{l}240^{\circ} \mathrm{C} \\
10 \mathrm{~min}\end{array}$} & $\mathrm{X}$ & $\mathrm{O}$ \\
\hline MACM & & BF6 (1) & $3-\mathrm{AB}(2)$ & & $\mathrm{X}$ & $\mathrm{O}$ \\
\hline FACP & \multirow{2}{*}{$6 \mathrm{FDA}(5)$} & $\mathrm{DAB}(3)$ & $4-\mathrm{AB}(2)$ & & $\mathrm{X}$ & $\mathrm{O}$ \\
\hline FACM & & & $3-\mathrm{AB}(2)$ & & $\mathrm{O}$ & $\mathrm{O}$ \\
\hline
\end{tabular}

the polyimides with the use of $\mathrm{DAB}$ co-monomer which will increase the solubility of the resulting polyimides in the PGMEA solvent. However, only the polyimide (FACM) exhibited solubility in PGMEA solvent up to $30 \mathrm{wt} \%$. This result of low solubility in PGMEA could be explained to be due to the intermolecular charge transfer complex (CTC) formation among the imide units linked by less sterically hindered major DAB co-monomers as shown in Figure 6.

Therefore, melt polymerization of polyimides were attempted without DAB co-monomer as shown in Figure 2 utilizing MCDA as dianhydride, BF6 as diamine and 4- $\mathrm{AB}$ or 3-AB as monoamines. The resulting polyimides MBBP and MBBM were all soluble in PGMEA up to $30 \mathrm{wt} \%$ as shown in Table 2. It was also noted the MBBP and MBBM polyimides could be melt polymerized at $240^{\circ} \mathrm{C}$ up to $60 \mathrm{~min}$ in the electric furnace. These difference in melt polymerization and solubility in PGMEA compared to the previous FTAP-1 in Figure 5, and MACP (M) and FACP (M) polyimides in Figure 1 could be explained by exchange of AH6 diamine monomer with $\mathrm{BF} 6$, and elimination of $\mathrm{DAB}$ co-monomer. In the MBBP and MBBM polyimides no cross-linking reaction could occur due to the absence of phenolic - $\mathrm{OH}$ groups thus melt polymerization time could be extended up to 60 minutes. The improved solubility of MBBP and MBBM could be also explained by less CTC formation by removing DAB units which could make CTC easier than BF6 diamine monomer due to less steric hindrance. The higher molecular weights of MBBM than MBBP may be explained by close melting points of $\mathrm{MCDA} / \mathrm{BF} / 3-\mathrm{AB}$ than $\mathrm{MCDA} / \mathrm{BF} 6 / 4-\mathrm{AB}$ set of monomers thus promoting the melt polymerization to occur under more homogeneous state during short period of time as shown in Table 2.

The FT-IR analyses of MBBP-3 and MBBM-3 polyimides in Figure 7 exhibited all the typical imide linkages as carbonyl group stretching $\left(1712 \mathrm{~cm}^{-1}\right)$, aromatic $-\mathrm{C}=\mathrm{C}-\left(1502 \mathrm{~cm}^{-1}\right)$ and aryl-aryl ether $\mathrm{C}-\mathrm{O}$ stretching $(1171-1246$ $\mathrm{cm}^{-1}$ ) while the other characteristic absorption peaks were observed at different points corresponding to the chemical groups in MBBP-3 and MBBM3.

\subsection{Solution Polymerization of Polyimides}

In order to further enhance the thermal stability of polyimides while retaining the solubility in organic solvent, we tried to synthesize double bond containing polyimides and to proceed UV curing. We utilized one-pot solution polymerization 


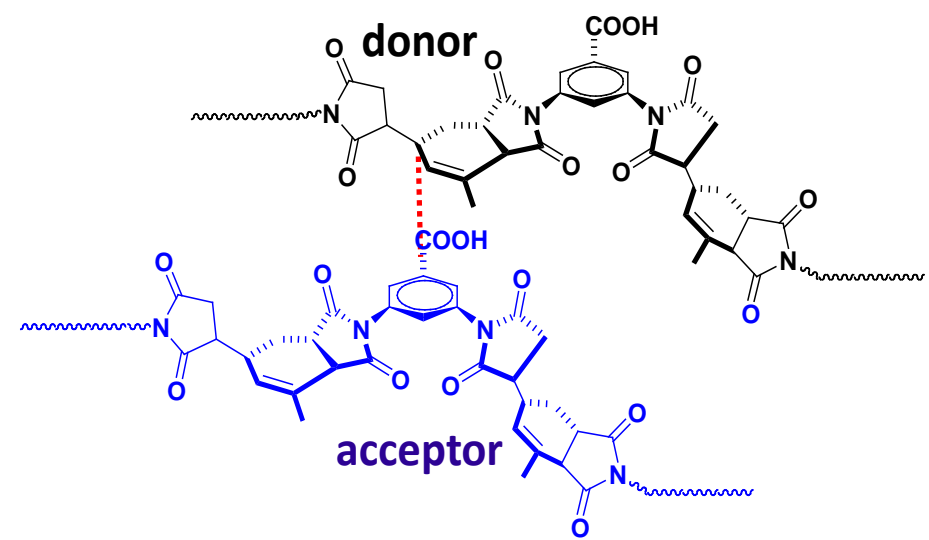

Figure 6. The schematic diagram of charge transfer complex formation by polyimides.

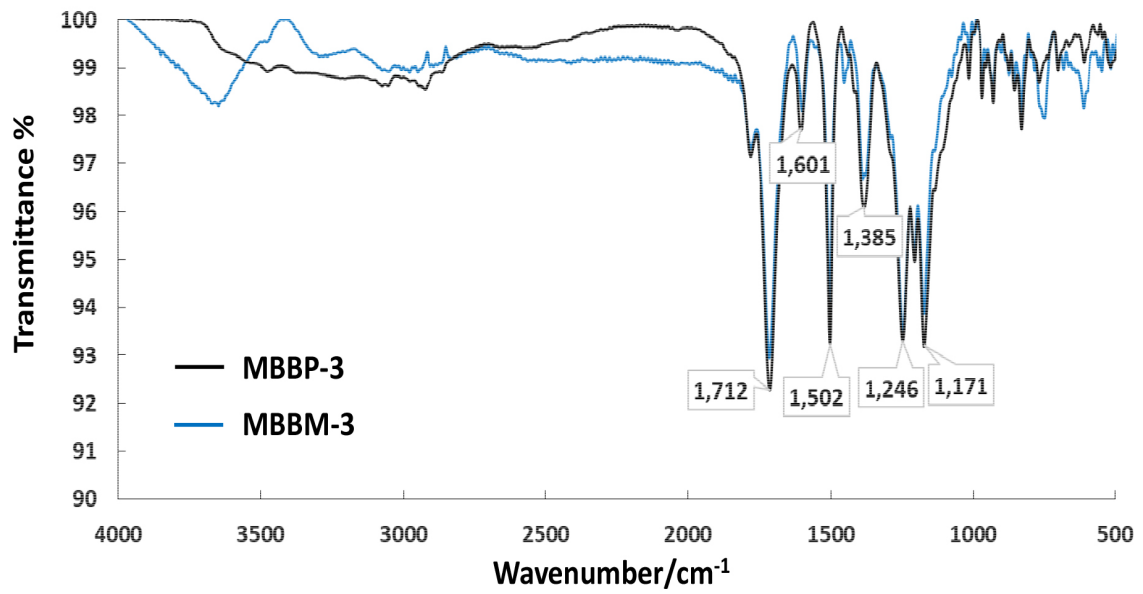

Figure 7. The FT-IR spectra of MBBP-3 and MBBM-3 polyimides.

Table 2. Molecular weights and thermal stabilities of MBBP and MBBM polyimide series.

\begin{tabular}{|c|c|c|c|c|c|c|}
\hline $\begin{array}{l}\text { Compound } \\
\text { Code }\end{array}$ & $\begin{array}{l}\text { Reactants } \\
(\mathrm{mmol})\end{array}$ & $\begin{array}{l}\text { Reaction } \\
\text { Time/min }\end{array}$ & GPC $\mathrm{M}_{\mathrm{w}}$ & $\begin{array}{c}1 \% \mathrm{WLT} /{ }^{\circ} \mathrm{C} \\
(\mathrm{TGA})^{\mathrm{a}}\end{array}$ & $\begin{array}{c}5 \% \mathrm{WLT} /{ }^{\circ} \mathrm{C} \\
(\mathrm{TGA})\end{array}$ & $\begin{array}{l}\text { PGMEA } \\
\text { solubility }\end{array}$ \\
\hline MBBP-1 & MCDA (5) & 10 & 4993 & 275 & 400 & \multirow{5}{*}{$\begin{array}{c}\text { All soluble } \\
\text { up to } 30 \\
\text { wt } \%\end{array}$} \\
\hline MBBP-2 & $\mathrm{T}_{\mathrm{m}}=172^{\circ} \mathrm{C}-176^{\circ} \mathrm{C}$ & 20 & 4562 & 326 & 398 & \\
\hline MBBP-3 & $\begin{array}{c}\text { AH6 (4) } \\
\mathrm{T}_{\mathrm{m}}=243^{\circ} \mathrm{C}\end{array}$ & 30 & 4745 & 338 & 411 & \\
\hline MBBP-4 & $4-\mathrm{AB}(2)$ & 40 & 3486 & 235 & 391 & \\
\hline MBBP-6 & $\mathrm{T}_{\mathrm{m}}=188^{\circ} \mathrm{C}$ & 60 & 4238 & 252 & 391 & \\
\hline MBBM-1 & MCDA (5) & 10 & 4121 & 287 & 383 & \multirow{5}{*}{$\begin{array}{c}\text { All soluble } \\
\text { up to } 30 \\
\text { wt } \%\end{array}$} \\
\hline MBBM-2 & $\mathrm{T}_{\mathrm{m}}=172^{\circ} \mathrm{C}-176^{\circ} \mathrm{C}$ & 20 & 5348 & 318 & 385 & \\
\hline MBBM-3 & $\mathrm{T}_{\mathrm{m}}=243^{\circ} \mathrm{C}$ & 30 & 6428 & 346 & 400 & \\
\hline MBBM-4 & $\begin{aligned} & 3-\mathrm{AB}(2) \\
\mathrm{T}_{\mathrm{m}}= & 178^{\circ} \mathrm{C}-180^{\circ} \mathrm{C}\end{aligned}$ & 40 & 4983 & 266 & 385 & \\
\hline MBBM-6 & & 60 & 3694 & 285 & 364 & \\
\hline
\end{tabular}

${ }^{a}$ WLT: weight loss temperature. 
for the synthesis of photocurable polyimides since double bonds undergo thermal cross-linking at melt polymerization temperature.

As shown in Figure 3, we first synthesized the intermediate SAM using MCDA as dianhydride, AH6 as diamine and AIPA as monoamine monomer in DMAc solvent. In the second step the carboxyl groups of the SAM intermediate were converted to methacrylate groups to give final product SAMG polyimides with two double bonds at both terminal which could be cured by UV exposure after spin coating and soft bake on the substrate.

The FT-IR chart of SAMG, PAMG and MAMG polyimides in Figure 8 showed similar peaks as MBBP and MBBM polyimides (Figure 7) since both series of polymers shared the same main-chain polyimide scaffold. In case of these 3 polyimides, the peaks around $1200 \mathrm{~cm}^{-1}$ were shrunk due to the absence of arylaryl ether.

Since the SAMG polyimide was prepared in the DMAc solvent which is known as a carcinogen to human, we tried to synthesize polyimide in environmentally friendly PGMEA solvent by using one-pot reaction method. We used the same MCDA and AH6 as dianhydride and diamine monomer but replaced AIPA with 4- $\mathrm{AB}$ (or 3- $\mathrm{AB}$ ) as monoamine monomer. This was due to the solubility difference of 4-AB/3-AB monomers with AIPA monomer; the former had high solubility in PGMEA, while the latter was not soluble in PGMEA. One-pot solution polymerization of PAMG and MAMG polyimides are shown in Figure 4 in which the intermediate is omitted since it was used directly in the second step. These PAMG and MAMG polyimides were obtained with 4-AB and 3-AB as monoamines, respectively. The GPC molecular weights of SAMG $(2578 \mathrm{~g} / \mathrm{mol})$ and MAMG-3 $(2475 \mathrm{~g} / \mathrm{mol})$ were similar as shown in Figure 9.

\subsection{Thermal Stability Tests}

We first checked the thermal stability of the MBBP and MBBM polyimides, which were synthesized by melt polymerization method. As shown in Table 2 of the MBBP and MBBM series polyimides, MBBP-3 and MBBM-3 exhibited the highest thermal stability as shown by $1 \mathrm{wt} \%$ and $5 \mathrm{wt} \%$ loss temperatures ( 1 WLT and 5 WLT) of the samples (Figure 10). The high thermal stability of MBBP-3 and MBBM-3 may be explained by the characteristics of the melt polymerization. As the melt polymerization time increased from $10 \mathrm{~min}$ to $30 \mathrm{~min}$ the conversion of melt polymerization could increase, thus improving the thermal stability, however after $30 \mathrm{~min}$ the partial degradation of polyimide may occur due to the accumulated heat in the electric oven leading to both low $\mathrm{Mw}$ and low thermal stability of the polyimides.

The TGA data of the solution polymerized SAMG and MAMG polyimides are shown in Figure 11 and Figure 12. The SAMG and MAMG polyimide solutions were first spin coated without UV photoinitiator (SPI-03) and subjected to TGA analysis of which TGA samples were recorded as SAMG (a) and MAMG (a) in Figure 11 and Figure 12, respectively. The other samples were spin coated 


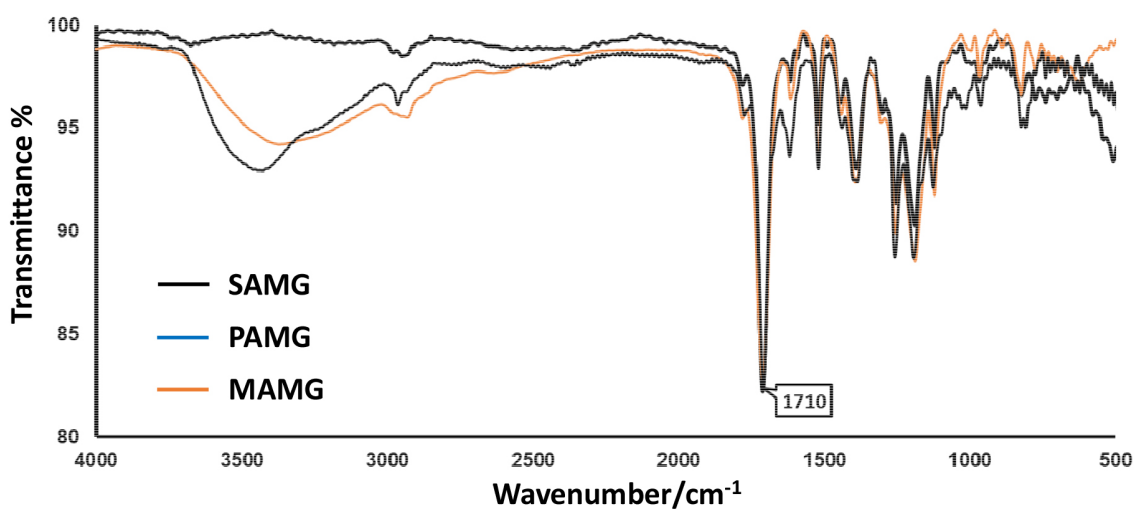

Figure 8. The FT-IR spectrum of SAMG, PAMG and MAMG polyimides.

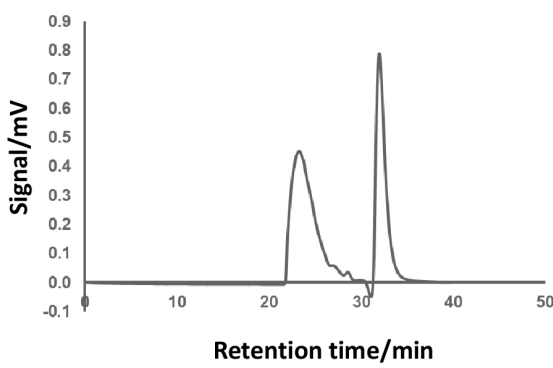

(a)

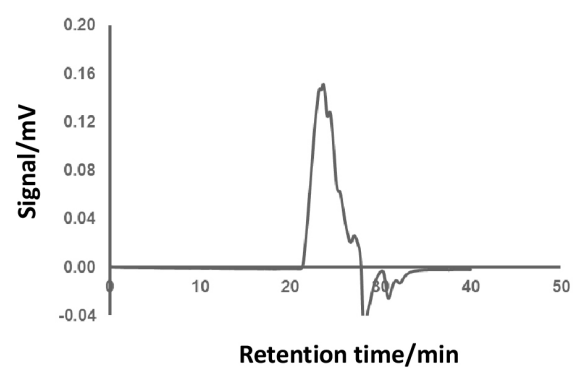

(b)

Figure 9. The GPC graphs of (a) SAMG and (b) MAMG-3 polyimides.

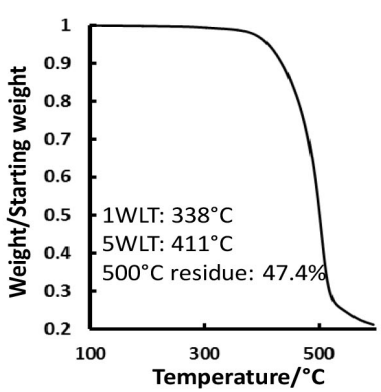

(a)

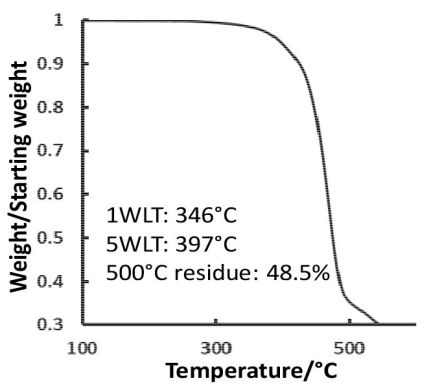

(b)

Figure 10. The thermal stability of MBBP-3 (a) and MBBM-3 (b) polyimides measured by TGA.

with the SAMG and MAMG solution containing SPI-03 photoinitiator followed by TGA process to give the thermogram of SAMG (b) and MAMG (b) in Figure 11 and Figure 12, respectively. The thermal stability of MAMG polyimide was higher than that of SAMG polyimide while both samples can be crosslinked by thermally or photochemically with photoinitiator. The low thermal stability of SAMG compared to the MAMG may be due to the incomplete removal of DMAc solvent in the spin coating and soft bake steps compared with PGMEA solvent.

It is of interest to notice the difference of the TGA residue data at $500^{\circ} \mathrm{C}$ of the MBBP/MBBM and SAMG/MAMG polyimide samples, while the former was in 


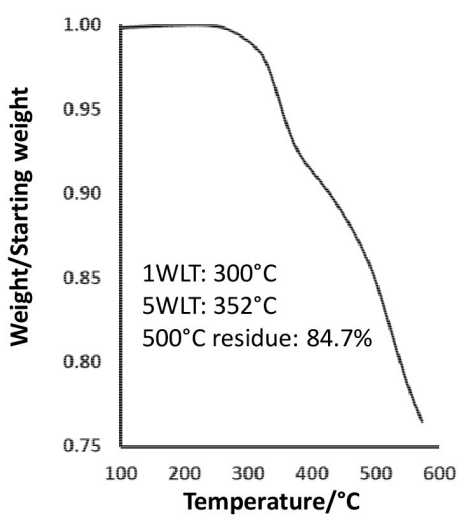

(a)

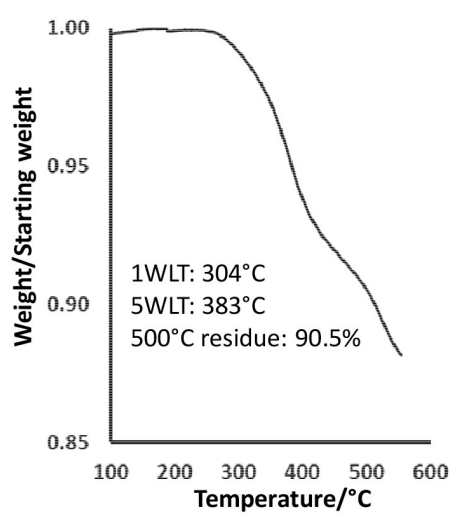

(b)

Figure 11. The TGA thermographs of (a) SAMG and (b) cured SAMG.

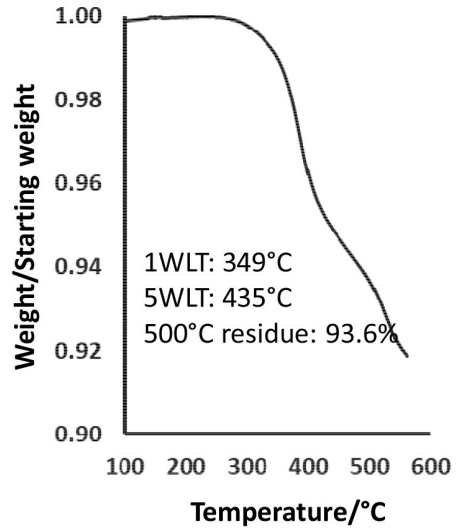

(a)

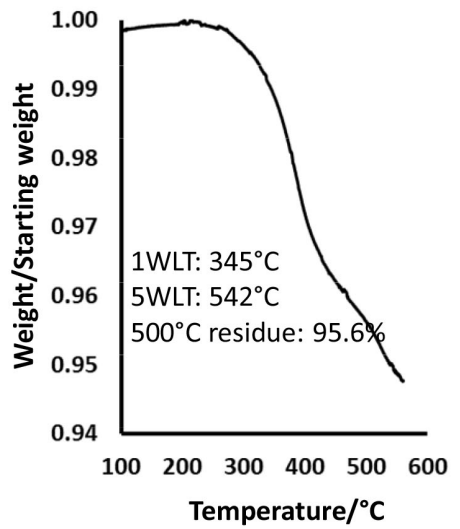

(b)

Figure 12. The TGA thermographs of (a) MAMG and (b) cured MAMG.

the range of $47.4 \%-48.5 \%$ and the latter, $84.7 \%-95.6 \%$. This difference of the TGA $500^{\circ} \mathrm{C}$ residue data is due to the different synthetic methods, the former by melt polymerization, and the latter by solution polymerization. In the melt polymerization of polyimides the exact stoichiometric balances of the monomers are hard to match compared to the solution polymerization. Another reason is the SAMG/MAMG polyimides can be cross-linked by the presence of the terminal double bonds while MBBP/MBBM polyimides could not be cross-linked in the absence of double bonds.

\section{Conclusion}

In this work we reported the melt and one-pot solution synthesis of acidic organosoluble and photocurable new polyimides and analyzed their thermal stability before and after UV curing. In the melt polymerization of MBBM and MBBM series polyimides high molecular polyimides could be obtained by using BF6 as diamine monomer which could not undergo thermal crosslinking reaction under melt polymerization conditions. In the solution polymerization of polyi- 
mides, the MAMG polyimide with two terminal double bonds exhibited higher thermal stability than SAMG polyimide with four terminal double bonds. Both MAMG and SAMG polyimides exhibited higher thermal stability by UV curing which could lead to crosslinking reaction than the same uncured polyimide samples. It was also noted that the UV curing of polyimide samples could enhance the thermal stability to much higher extent than that of melt polymerized polyimides.

\section{Acknowledgements}

This work was supported by the Technology Innovation Program (or Industrial Strategic Technology Development Program, 10063289, Development of High Temperature Negative tone Photosensitive Black Resin and Fabrication Process for Pol-less AMOLED Devices) funded by the Ministry of Trade, Industry \& Energy(MOTIE, Korea).

\section{Conflicts of Interest}

The authors declare no conflicts of interest regarding the publication of this paper.

\section{References}

[1] Ji, D., Li, T., Hu, W. and Fuchs, H. (2019) Recent Progress in Aromatic Polyimide Dielectrics for Organic Electronic Devices and Circuits. Advanced Materials, 31, Article ID: 1806070. https://doi.org/10.1002/adma.201806070

[2] Ding, Y., Hou, H., Zhao, Y., Zhu, Z. and Fong, H. (2016) Electrospun Polyimide Nanofibers and Their Applications. Progress in Polymer Science, 61, 67-103. https://doi.org/10.1016/j.progpolymsci.2016.06.006

[3] Li, G., Zhang, B., Yan, J. and Wang, Z. (2016) Microporous Polyimides with Functional Groups for the Adsorption of Carbon Dioxide and Organic Vapors. Journal of Materials Chemistry A, 4, Article ID: 11453. https://doi.org/10.1039/C6TA04337B

[4] Ahmad, M.B., Gharayebi, Y., Salit, M.S., Hussein, M.Z., Ebrahimiasl, S. and Dehzangi, A. (2012) Preparation, Characterization and Thermal Degradation of Polyimide (4-APS/BTDA)/ $/ \mathrm{SiO}_{2}$ Composite Films. International Journal of Molecular Sciences. 13, 4860-4872. https://doi.org/10.3390/ijms13044860

[5] Huang, X., Chen, B., Mei, M., Li, H., Liu, C. and Wei, C. (2017) Synthesis and Characterization of Organosoluble, Thermal Stable and Hydrophobic Polyimides Derived from 4-(4-(1-Pyrrolidinyl)phenyl)-2,6-bis (4-(4-aminophenoxy)phenyl)pyridine. Polymers, 9, 484. https://doi.org/10.3390/polym9100484

[6] Kim, E., Yi, M.H. and Ahn, T. (2016) Low-Temperature Photo-Curable Polyimides as Gate Insulators for Thin-Film Transistors. Journal of Nanoscience and Nanotechnology, 16, 11762-11765. https://dx.doi.org/10.1166/jnn.2016.13589

[7] Guo, Y., Ji, Z., Zhang, Y., Wang, X. and Zhou, F. (2017) Solvent-Free and Photocurable Polyimide Inks for 3D Printing. Journal of Materials Chemistry A, 5, Article ID: 16307. https://doi.org/10.1039/C7TA01952A

[8] Herzberger, J., Meenakshisundaram, V., Williams, C.B. and Long, T.E. (2018) 3D Printing All-Aromatic Polyimides Using Stereolithographic 3D Printing of Polya- 
mic Acid Salts. ACS Macro Letters, 7, 493-497.

https://doi.org/10.1021/acsmacrolett.8b00126

[9] Shi, G., Park, J. W. and Park, L. S. (2018) Black Photoresist for Patterning Pixel Define Layer of Organic Light Emitting Diode with Polyimide as Thermal Stabilizer. Materials Sciences and Applications, 9, 554-564.

https://doi.org/10.4236/msa.2018.96040 